\title{
VIABILIDADE ECONÔMICA DA TERCEIRA ORDENHA EM SISTEMAS DE PRODUÇÃO DE LEITE COM ORDENHA MANUAL
}

\author{
Marcos Aurélio Lopes ${ }^{1}$, Gastão Lemos Barbosa ${ }^{2}$, TATIANe MendonÇA NogUeirA ${ }^{3}$ \\ ${ }^{1}$ Professor Doutor da Universidade Federal de Lavras, bolsista do CNPq, Lavras, MG, Brasil. malopes@ dmv.ufla.br \\ ${ }^{2}$ Pós-graduando da Universidade Federal de Lavras, Lavras, MG, Brasil. \\ ${ }^{3}$ Graduanda em Medicina Veterinária da Universidade Federal de Lavras, Lavras, MG, Brasil.
}

\begin{abstract}
Objetivou-se analisar a viabilidade econômica da terceira ordenha em sistemas de produção de leite utilizando ordenha manual, visando fornecer aos técnicos $\mathrm{e}$ pecuaristas informações que os auxiliem no processo de tomada de decisões. Especificamente, pretendeu-se, ainda: a) estimar o custo de uma ordenha; b) estimar o custo da terceira ordenha utilizando mão de obra contratada e familiar; c) desenvolver uma equação matemática que permita estimar a quantidade mínima de leite produzida em duas ordenhas, a partir da qual será economicamente viável a realização da terceira ordenha. Os dados foram coletados em três sistemas de produção de leite no período de novembro de 2010 a março de 2011 , em uma rotina de
\end{abstract}

duas ordenhas diárias, sendo realizadas três coletas de dados em cada um, perfazendo um total de nove. Considerando-se os dados médios, seria viável a realização da terceira ordenha se a produtividade média diária por vaca em lactação em duas ordenhas fosse igual ou superior a 157,75 e $9,20 \mathrm{~kg}$ de leite, se a mão de obra fosse contratada e familiar, respectivamente. A equação matemática desenvolvida pode auxiliar o técnico e o pecuarista estimar a quantidade mínima de leite produzida por uma vaca em duas ordenhas, a partir da qual será viável economicamente a realização da terceira ordenha, com precisão e considerável rapidez.

PALAVRAS-CHAVE: bovinocultura leiteira; custo de produção; economia; frequência de ordenhas; mão de obra familiar.

\section{ECONOMIC VIABILITY OF THE THIRD MILKING IN SYSTEMS OF MILK PRODUCTION USING HAND MILKING}

\section{ABSTRACT}

This study aimed to analyze the economic viability of the third milking in milk production systems using hand milking, aiming to provide information to technicians and farmers to help in the decision-making process. Specifically, we intended a) to estimate the cost of a milking; (b) to estimate, by means of simulation, the cost of the third milking using hired or family labor; (c) to develop a mathematical equation that allows estimating the minimum amount of milk produced in two milkings, from which it will be economically feasible to carry out the third milking. The data were collected in three milk production systems from November 2010 to March 2011, in a routine of two milkings per day, with three collections of data in each one, totaling nine. Considering the average data, it would be feasible to hold the third milking if the productivity of daily average lactating cows would be equal or greater than 157.75 and $9.20 \mathrm{~kg}$ of milk, with hired or family labor, respectively. The mathematical equation developed may help the technician and the farmer to estimate quickly and precisely the minimum quantity of milk produced by a cow in two milkings, from which it will be economically feasible to keep the third milking.

KEYWORDS: cost of production; dairy cattle; economy; family labor; frequency of milking. 


\section{INTRODUÇÃO}

A terceira ordenha é utilizada por várias propriedades leiteiras como recurso para "diluir" os custos fixos e aumentar a produção de leite, otimizando, assim, a infraestrutura dos sistemas de produção leiteira.

O aumento da produção de leite é, certamente, a mais consistente e importante resposta ao aumento da frequência de ordenhas. Entretanto, outros efeitos devem ser avaliados antes de se tomar a decisão de adotar, ou não, essa prática; entre eles, o mais importante é o custo dessa terceira ordenha. Surge, então, uma pergunta: a partir de quantos litros de leite/vaca/dia é viável, economicamente, a adoção da terceira ordenha em uma propriedade leiteira?

Resultados de pesquisas demonstram as vantagens e limitações da realização de tal prática, tais como o aumento na produção de leite (BERNIERDODIER et al., 2010), alteração na composição do leite (KLEI et al., 1997), efeito sobre a saúde e reprodução (MOYA et al., 2008) e no consumo de alimentos e metabolismo (SMITH et al., 2002). Entretanto, nenhum estudo abordou efeitos sobre a viabilidade econômica.

Alguns poucos pesquisadores apenas salientaram que o aumento na frequência acarreta mais gastos com alimentação, mão de obra, maquinário de ordenha e implementos utilizados na ordenha: soluções desinfetantes, papel toalha, água, entre outros (DAHL, 2005). As raras pesquisas que mencionam algo sobre os custos, somente citam itens que serão gastos, sem resposta alguma quanto ao custo de tal prática e a viabilidade econômica dessa terceira ordenha, deixando, assim, o produtor sem parâmetro confiável para tomar a decisão de implantação. Nas fazendas, nota-se, muito claramente, essa falta de informação e, consequentemente, a implantação da terceira ordenha de forma errônea, levando, muitas vezes, à descapitalização, em médio prazo, do produtor.

Diante da importância do assunto e da escassez de informações, resolveu-se realizar esta pesquisa, cujo objetivo foi analisar a viabilidade econômica da terceira ordenha em sistemas de produção de leite, utilizando-se ordenha manual, discutindo suas vantagens e limitações, visando fornecer aos técnicos e pecuaristas informações que os auxiliem no processo de tomada de decisões. Especificamente, pretendeu-se ainda: a) estimar o custo operacional de uma ordenha; b) estimar, por meio de simulação, o custo operacional da terceira ordenha utilizando mão de obra contratada e familiar; c) desenvolver uma equação matemática que permita estimar a quantidade mínima de leite produzida por uma vaca em duas ordenhas, a partir da qual será viável economicamente a realização da terceira ordenha.

\section{MATERIAL E MÉTODOS}

Os dados foram coletados, no período de novembro de 2010 a março de 2011, em três sistemas de produção de leite, cujas características estão compiladas na Tabela 1 , com rotina de duas ordenhas diárias, sendo realizadas três coletas em cada um, perfazendo um total de nove. Foram anotadas as quantidades de produtos gastos, bem como suas especificações, visando uma orçamentação mais criteriosa, bem como maior precisão na estimativa do custo da realização da ordenha. Estimou-se ainda o consumo de energia elétrica em cada ordenha, o que correspondeu à soma do consumo das lâmpadas e motor elétrico da bomba para lavar as instalações, além de outros gastos.

Realizou-se ainda o levantamento de todos os materiais e equipamentos utilizados no processo de ordenha, tais como: balde de leite, coador de leite, copo para higiene, corda, enxada e rodo de ferro (para a limpeza das fezes do local), lâmpadas das salas de ordenha e do curral, latão de leite, correia para o motor elétrico, avental, vassoura, bota de borracha (para uso do retireiro), luvas de procedimento, além de outros gastos que foram específicos de cada sistema de produção de leite.

Visando analisar o custo da mão de obra, foi ainda registrado o horário de início e término do trabalho dos ordenhadores, desde o momento em que buscaram os animais no pasto até o término do processo de ordenha, com a liberação dos animais para o pasto.

$\mathrm{O}$ registro dos dados foi realizado em uma planilha desenvolvida especialmente para esta pesquisa, na qual consta o nome do produto utilizado, sua especificação, valor unitário, quantidade gasta e o total, em reais, do gasto com cada produto. A partir da soma de todos os gastos, obteve-se o custo operacional total do processo de uma ordenha, em reais $(\mathrm{R} \$)$, bem como as médias e desvios-padrão, por sistema de produção, por animal e por litro de leite.

Tendo em mãos o custo operacional médio por ordenha em tais sistemas, desenvolveu-se outra planilha objetivando estimar o custo operacional adicional da terceira ordenha diária. Para esse cálculo, foram considerados, além dos gastos normais, o custo adicional com energia elétrica e mão de obra. 
Tabela 1 - Algumas características dos sistemas de produção (SP) de leite analisados

\begin{tabular}{lccccc}
\hline Especificação & SP 1 & SP 2 & SP 3 & Média & DP \\
\hline Quantidade de animais ordenhados & 23,00 & 16,00 & 23,00 & 20,44 & 4,14 \\
Grupo genético & GH & $3 / 4$ HPB & GH & & \\
Produção total de leite/dia (L) & 273,33 & 143,33 & 181,33 & 199,33 & 66,84 \\
Produção média/animal/dia (L) & 11,88 & 9,14 & 7,99 & 9,67 & 1,99 \\
Valor médio do litro de leite (R\$) & 0,58 & 0,75 & 0,62 & 0,65 & 0,08 \\
\hline
\end{tabular}

$\mathrm{DP}=$ desvio padrão; HPB: holandês preto e branco; GH; Mestiço de Gir com Holandês.

Para a implantação da terceira ordenha, considerou-se a necessidade de um terceiro turno de serviço (pois uma das ordenhas será realizada entre 22 e 6 horas) com pagamentos de horas extras (50\% a mais que as normais), repouso semanal remunerado, férias, feriados, $13^{\circ}$ salário, $1 / 3$ de férias, previdência social, FGTS (Fundo de Garantia por Tempo de Serviço), seguro acidentes de trabalho, salário educação, SENAR (Serviço Nacional de Aprendizagem Rural), INCRA (Instituto Nacional de Colonização e Reforma Agrária), SEBRAE (Serviço Brasileiro de Apoio a Micro e Pequenas Empresas), totalizando 36,8\% do custo com mão de obra, além do pagamento do adicional noturno que, na área rural, é de $25 \%$ de acréscimo sobre a hora normal (MARTINS, 2008). Sendo assim, o custo adicional da mão de obra foi de $\mathrm{R} \$ 5,64$ por hora extra/noturna (o que significa um aumento de 75,3\% da hora normal).

Nesta pesquisa, o valor total das despesas com o trabalhador foi realizado com base nos encargos e no FGTS relacionados ao salário integral do funcionário e das provisões. $\mathrm{O}$ salário base utilizado foi de $\mathrm{R} \$ 545,00$. Realizou-se, ainda, uma simulação considerando que a mão de obra era familiar, não havendo desembolso pelo pecuarista (LOPES et al., 2007). Na estimativa dos custos, adotou-se a metodologia do Custo Operacional, proposta por MATSUNAGA et al. (1976).

Para se obter a resposta sobre a viabilidade econômica da terceira ordenha nos rebanhos estudados, desenvolveu-se uma equação matemática, pela qual se estima a produção mínima necessária para que a terceira ordenha seja viável economicamente.

Para a estimativa do aumento na produção de leite, decorrente da implantação da terceira ordenha, adotou-se o valor de $16,75 \%$, obtido por meio do cálculo da média dos valores citados por vários pesquisadores (VASCONCELLOS, 1975; AMOS et al., 1985; BAR-PELED et al., 1995; ERDMAN \& VARNER, 1995; HOMAN \& WATTIAUX, 1995; HEBERT, 2002; CAMINHA \& GONÇALVES, 2003; ALVES, 2004; NEGRÃO, 2004; DAHL, 2005; DIAS, 2005; GAMA \& LOPES, 2008).

\section{RESULTADOS E DISCUSSÕES}

O custo operacional total (COT) para realização de uma ordenha utilizando a técnica manual foi de $\mathrm{R} \$ 20,00( \pm 5,42)$ (Tabela 2$)$, que correspondeu à soma dos valores referentes aos itens depreciáveis $(\mathrm{R} \$ 0,16)$, ou seja, cuja utilização não varia por ordenha, com aqueles cujos consumos variam ( $\mathrm{R} \$ 19,84)$. A mão de obra foi o item de maior representatividade no COT, seguida pela depreciação dos equipamentos. Nesse último grupo, o item com maior representatividade foi o coador de leite. Observa-se que os produtos utilizados para uma obtenção higiênica do leite não foram utilizados. De acordo com LOPES et al. (2004), tal prática tem sido negligenciada por muitos pecuaristas. Esses pesquisadores, ao fazerem o levantamento de todas as despesas operacionais efetivas em 16 sistemas de produção de leite do sul de Minas Gerais, constataram que em 50\% não houve nenhuma despesa com aquisição de soluções pré e pós-dipping, detergentes ácidos e alcalinos, papel toalha, desinfetantes e demais produtos utilizados na ordenha. 
Tabela 2 - Custo operacional total (COT) para realização de uma ordenha utilizando-se ordenha manual

\begin{tabular}{lcccc}
\hline & \multicolumn{3}{c}{ Itens que depreciam } & \\
Item & Valor médio $(\mathrm{R} \$)$ & Depreciação media/ord $(\mathrm{R} \$)$ & $\%$ no item & $\%$ no total \\
\hline Na sala de ordenha & 580,10 & 0,161451 & 100,00 & 1,02 \\
Na sala de máquinas & 4,35 & 0,00 & 0,00 & 0,00 \\
Na sala de leite & 0,00 & 0,00 & 0,00 & 0,00 \\
Outros & 2,5 & 0,00 & 0,00 & 0,00 \\
Subtotal por ordenha & & 0,161451 & 100,00 & 0,80 \\
Subtotal por animal & & 0,007897 & & \\
Subtotal por litro de leite & & 0,001620 & & \\
\hline
\end{tabular}

\begin{tabular}{|c|c|c|c|c|}
\hline \multicolumn{5}{|c|}{ Itens de consumo } \\
\hline & Média $(\mathrm{R} \$)$ & DP & $\%$ no item & $\%$ no total \\
\hline Na sala de ordenha & 0,00 & 0,00 & 0,00 & 0,00 \\
\hline Na sala de máquinas & 0,00 & 0,00 & 0,00 & 0,00 \\
\hline Energia elétrica & 0,00 & 0,00 & 0,00 & 0,00 \\
\hline Mão de obra & 19,84 & 5,42 & 100,00 & 99,20 \\
\hline Subtotal por ordenha & 19,84 & 5,42 & 100,00 & 99,20 \\
\hline Subtotal por animal & 0,99 & 0,28 & & \\
\hline Subtotal por litro de leite & 0,20 & 0,04 & & \\
\hline \multicolumn{5}{|c|}{ Total Geral } \\
\hline COT/ordenha (R\$) & 20,00 & 5,42 & & 100,00 \\
\hline COT/animal (R\$) & 0,97 & 0,28 & & \\
\hline COT/litro de leite $(\mathrm{R} \$)$ & 0,20 & 0,04 & & \\
\hline
\end{tabular}

$\mathrm{DP}=$ desvio padrão; Ord $=$ ordenha

Tabela 3 - Custo operacional total (COT) para realização da terceira ordenha utilizando-se ordenha manual

\begin{tabular}{lccc}
\hline Especificação & Valor $(\mathrm{R} \$)$ & \% no custo adicional & \% no COT \\
\cline { 1 - 2 } Custos adicionais da terceira ordenha & & & \\
Mão de obra & 14,758000 & 99,49 & 42,35 \\
Energia elétrica & 0,075647 & 0,51 & 0,22 \\
\hline Total adicional & 14,833647 & 100,00 & 42,57 \\
\hline Custo da ordenha convencional & & & 57,42 \\
\hline Custo operacional total da ordenha & 20,009951 & & 100,00 \\
\hline COT (R\$) & 34,843598 & \\
COT /animal (R\$) & 1,704306 & \\
COT /litro de leite (R\$) & 0,349601 & & \\
\hline
\end{tabular}

O custo operacional total para a realização da terceira ordenha, utilizando-se técnica manual, foi de $\mathrm{R} \$ 34,84$ (Tabela 3), sendo $\mathrm{R} \$ 20,00$ referente a custo da ordenha convencional, praticada diurnamente, e $\mathrm{R} \$ 14,83$ de custo adicional, que correspondeu à soma dos valores referentes à mão de obra $(\mathrm{R} \$ 14,75 ; 99,49 \%)$ e energia elétrica $(\mathrm{R} \$ 0,07$; $0,51 \%)$.

O gasto com mão de obra teve um aumento expressivo, pois, com a implantação da terceira ordenha, haverá necessidade de um terceiro turno, o que implicará maior tempo de serviço, pagamentos de horas extras (50\% a mais que as normais) e encargos sociais. Sendo assim, o custo adicional da mão de obra foi de $\mathrm{R} \$ 5,64$ por hora extra noturna (o que significa um aumento de $75,3 \%$ da hora normal).

Caso o pecuarista venha adotar a terceira ordenha, é necessário salientar que haverá, também, um aumento no consumo de alimento concentrado. De acordo com LOPES et al. (2004), o custo total 
com alimentação pode chegar a até $60 \%$ das despesas operacionais efetivas, o que é de extrema importância. Com a implantação da terceira ordenha, há um aumento de produção de leite, com isso, a exigência da vaca também aumenta, necessitando de suplementação alimentar. Se a suplementação não for feita corretamente, o animal terá que suprir a necessidade gerada pelo aumento de produção, retirando de sua reserva corporal, levando a perda de peso e escore corporal, prejudicando todo seu metabolismo (KELLY et al., 1998; SMITH et al., 2002).

Conhecendo-se o custo operacional total da realização da terceira ordenha, necessita-se saber se ela é viável economicamente. Para a estimativa da quantidade mínima de leite produzida por uma vaca, diariamente, em duas ordenhas, de forma que haja viabilidade econômica da realização da terceira ordenha, desenvolveu-se a equação 1 . Ela é função:

a) da produção total de leite/dia do sistema de produção, em kg;

b) do custo operacional total da terceira ordenha, em R\$, que corresponde ao somatório de todos os gastos com soluções pré e pós-dipping, detergentes ácidos e alcalinos, papel toalha, desinfetantes e demais produtos utilizados na ordenha, bem como com mão de obra e com a depreciação de equipamentos, ferramentas e utensílios, por terem vida útil superior a um ciclo produtivo que, no caso da atividade leiteira, considera-se um ano;

c) do preço recebido por $\mathrm{kg}$ de leite, pelo pecuarista, em R\$;

d) do custo variável médio, em $\mathrm{R} \$$, por $\mathrm{kg}$ de leite, o que corresponde aos gastos com alimentação, mão de obra, sanidade, energia (elétrica e combustíveis), reprodução, bem como com despesas diversas;

e) da quantidade de animais ordenhados por dia; f) do aumento de produção total diária de leite/dia, em kg, advindo da implantação da terceira ordenha, que, no caso em questão, considerou-se um aumento de $16,75 \%$, o que correspondeu à média de resultados obtidos por diversos pesquisadores.

$$
\mathbf{P M}=\frac{\left(\mathbf{P F}+\frac{\mathbf{C O}}{\mathbf{P L}-\mathbf{C V}}\right)}{\mathbf{Q A}} \times \frac{\mathbf{P F}}{(\text { Equação 1) }}
$$

Em que:

$\mathrm{PM}=$ Produção mínima de leite vaca/dia desejada para tornar a terceira ordenha economicamente viável, em kg;

$\mathrm{PF}=$ Produção de total de leite/dia do sistema de produção (fazenda), em kg;

$\mathrm{CO}=$ Custo operacional total da terceira ordenha, em R\$;

$\mathrm{PL}=$ Preço recebido por $\mathrm{kg}$ de leite, em $\mathrm{R} \$$;

$\mathrm{CV}=$ Custo variável de um $\mathrm{kg}$ de leite produzido no sistema de produção, em $\mathrm{R} \$$;

$\mathrm{QA}=$ Quantidade de animais ordenhados por dia;

$\mathrm{AP}=$ Aumento de produção diária total de leite/dia, em kg, com a terceira ordenha.

No exemplo em questão, considerando-se os dados médios, coletados em três sistemas de produção de leite, que utilizam ordenha manual (Tabela 1), e a inserção dos respectivos valores na equação 1 , seria viável a realização da terceira ordenha se a produtividade média diária, por vaca em lactação, fosse igual ou superior a $157,75 \mathrm{~kg}$ de leite (Figura 1). Nos sistemas estudados nesta pesquisa, a produtividade diária média, por vaca em lactação, foi de 9,67kg $( \pm 1,99)$ de leite (Tabela 1). Com o aumento de 16,75\%, (obtido por meio do cálculo da média dos valores citados por vários pesquisadores) advindo da implantação da terceira ordenha, a produtividade subiria para $11,29 \mathrm{~kg} / \mathrm{vaca}$ em lactação; valor bem abaixo do mínimo para tornar a terceira ordenha viável economicamente.

$$
\begin{array}{r}
P M=\frac{\left(P F+\frac{C O}{P L-C V}\right)}{Q A} \times \frac{P F}{P F+A P} \\
P M=\frac{\left(199,33+\frac{34,84}{0,65-0,64}\right)}{20,00} \times \frac{199,33}{199,33+33,38}
\end{array}
$$

$P M=157,75 \mathrm{~kg}$ de leite

Figura 1 - Exemplo de aplicação da equação matemática desenvolvida 
Substituindo, individualmente, os valores de cada um dos sistemas de produção estudados (Tabela 1), na equação 1, verifica-se que não é possível estimar as produções nos sistemas 1 e 3 , pois o valor de venda do leite é inferior ao custo variável unitário, conforme equações abaixo, ou seja, a produção de leite está sendo anti-econômica nesses dois sistemas de produção, o que significa que a implantação da terceira ordenha implicaria ainda em maiores custos e prejuízos. Em relação ao sistema de produção 2, apesar da margem de contribuição ser positiva, não seria viável a realização de tal prática, pois a produtividade de $10,68 \mathrm{~kg}$ de leite/vaca em lactação ficaria abaixo da quantidade mínima estimada de $23,62 \mathrm{~kg}$.

Embora os grupos genéticos dos sistemas de produção 1 e 3 sejam semelhantes, a produção média/animal/dia foi diferente, devido à melhor alimentação fornecida aos animais do sistema 1 , que também foi melhor do que a fornecida aos animais do sistema 2, que possuem maior caracterização da raça holandesa. No entanto, o principal fator que tornou a realização da terceira ordenha viável economicamente foi o valor do $\mathrm{kg}$ de leite, recebido pelo pecuarista, que foi superior ao custo variável unitário, tornando a margem de contribuição positiva.

$$
\begin{aligned}
& \mathbf{P M}=\frac{\left(273,33+\frac{35,74}{0,58-0,64}\right)}{23,00} \times \frac{273,33}{273,33+45,78} \quad(\text { Sistema } 1) \\
& \mathbf{P M}=\frac{\left(143,33+\frac{32,77}{0,75-0,64}\right)}{16,00} \times \frac{143,33}{143,33+24,00} \quad \mathbf{P M}=23,62 \mathrm{~kg} \quad(\text { Sistema } 2) \\
& \mathbf{P M}=\frac{181,33+\frac{26,86}{0,62-0,64}}{23,00} \times \frac{181,33}{181,33+30,37} \quad(\text { Sistema } 3)
\end{aligned}
$$

Os três sistemas de produção estudados et al., 1976), decidiu-se realizar uma simulação possuem mão de obra familiar para realizar a desconsiderando-se tal valor (Tabela 4). Justifica-se ordenha. Considerando que tal componente foi a realização de tal estudo, pois ele terá uma boa responsável por $99,49 \%$ do custo operacional total aplicabilidade, uma vez que $84,4 \%$ dos das despesas adicionais para realização da terceira estabelecimentos agropecuários do país possuem ordenha e que ele não constitui em desembolso para esse tipo de mão de obra (IBGE, 2006).

o pecuarista (LOPES et al., 2007 e MATSUNAGA

Tabela 4 - Custo operacional total (COT) para a realização da ordenha manual, considerando (CMO) e não considerando o custo com mão de obra (NMO)

\begin{tabular}{lcccc}
\hline & \multicolumn{2}{c}{ CMO } & \multicolumn{2}{c}{ NMO } \\
\cline { 2 - 5 } Especificação & Média (R\$) & DP & Média (R\$) & DP \\
\cline { 2 - 5 } COT/ordenha (R\$) & 20,009 & 5,421 & 0,161 & 0,000 \\
COT/animal (R\$) & 0,978 & 0,281 & 0,007 & 0,002 \\
COT/litro de leite (R\$) & 0,200 & 0,048 & 0,001 & 0,000 \\
\hline
\end{tabular}

No exemplo em questão, não considerando o valor da mão de obra (em caso de mão de obra familiar) e a inserção dos valores na equação 1 , seria viável a realização da terceira ordenha se a produtividade média diária por vaca em lactação fosse igual ou superior a 9,52kg de leite (Figura 2). Nos sistemas estudados nesta pesquisa, a produtividade diária média foi de $9,67 \mathrm{~kg}( \pm 1,99)$ de leite/vaca (Tabela 1). Com o aumento de 16,75\%, (obtido através do cálculo da média dos valores citados por vários pesquisadores) advindo da implantação da terceira ordenha, a produtividade subiria para $11,29 \mathrm{~kg}$ de leite/vaca em lactação; valor bem acima do mínimo para tornar a terceira ordenha viável economicamente. Ou seja, se o sistema de produção que representa a média não considerar os valores referentes à mão de obra, a realização da terceira ordenha é viável economicamente. 


$$
\begin{gathered}
P M=\frac{\left(P F+\frac{C O}{P L-C V}\right)}{Q A} \times \frac{P F}{P F+A P} \\
P M=\frac{\left(199,33+\frac{0,23}{0,65-0,64}\right)}{20,00} \times \frac{199,33}{199,33+33,38}
\end{gathered}
$$

$\mathrm{PM}=9, \mathbf{5 2} \mathrm{kg}$

Figura - 2 Exemplo de aplicação da equação matemática desenvolvida

Substituindo, individualmente, os valores do sistema de produção 2 (Tabela 1), na equação 1 , verifica-se que não seria viável a realização de tal prática, pois a produtividade de $10,68 \mathrm{~kg}$ de leite/vaca em lactação ficaria abaixo da quantidade mínima $(14,59 \mathrm{~kg})$.

$$
\begin{gathered}
\mathbf{P M}=\frac{\left(273,33+\frac{9,95}{0,58-0,64}\right)}{23,00} \times \frac{273,33}{273,33+45,78} \quad(\text { Sistema } 1) \\
\mathbf{P M}=\frac{\left(143,33+\frac{14,21}{0,75-0,64}\right)}{16,00} \times \frac{143,33}{143,33+24,00} \quad \mathbf{P M}=\mathbf{1 4 , 5 9 k g}(\text { Sistema }) \\
\mathbf{P M}=\frac{181,33+\frac{11,67}{0,62-0,64}}{23,00} \times \frac{181,33}{181,33+30,37} \quad(\text { Sistema } 3)
\end{gathered}
$$

Considerando que a produção mínima é função da produção total de leite/dia do sistema de produção, em $\mathrm{kg}$, do custo operacional total da terceira ordenha, do preço recebido por $\mathrm{kg}$ de leite, do custo variável médio do leite, da quantidade de animais ordenhados e do aumento de produção total diária de leite/dia, em $\mathrm{kg}$, com a terceira ordenha (equação 1 e Figura 1), o pecuarista possui algumas alternativas para reduzir a quantidade mínima de leite. A principal alternativa seria aumentar a margem de contribuição, que é a diferença entre o preço do leite (PL) e o custo variável (CV). O pecuarista, por ser um tomador de preços, pouco pode influenciar no preço do leite, exceto quando produz maiores quantidades e leite com melhor qualidade, recebendo bonificações (LOPES et al., 2008). No entanto, ele pode concentrar esforços gerenciais e ou tecnológicos visando reduzir os custos de produção do leite (total, fixos, variáveis e operacionais) (LOPES et al., 2008). Reduzindo os custos variáveis, a quantidade mínima de leite a ser produzida para custear as despesas da terceira ordenha (CO) seria menor, o que influencia significativamente no valor estimado pela equação.

A segunda alternativa seria trabalhar com vacas de alta produção, pois tanto os custos fixos, que representaram $0,80 \%$, como os variáveis $(99,20 \%)$ (Tabela 2) da realização de uma ordenha (CO, na equação 1) seriam "diluídos", reduzindo ainda mais os custos variáveis de produção do leite, aumentando, assim, a margem de contribuição. A maior produção, em duas ordenhas, implicaria em maior quantidade resultante do aumento percentual da produção, cujo valor adotado na presente pesquisa foi de $16,75 \%$.

Uma terceira alternativa, no caso de pequenos produtores, seria a utilização da mão de obra familiar, pois as despesas com mão de obra representaram 99,49\% das despesas adicionais e $42,35 \%$ das despesas totais da realização da terceira ordenha (Tabela 3), devido aos valores referentes à hora extra e ao adicional noturno.

\section{CONCLUSÕES}

Considerando os dados médios, coletados em três sistemas de produção de leite que utilizam ordenha manual, é viável a realização da terceira ordenha apenas se a mão de obra for familiar, devido à baixa produtividade dos animais e, principalmente, aos custos adicionais com hora extra e adicional noturno. 
A equação matemática desenvolvida pode auxiliar o técnico e o pecuarista a estimar, com precisão e considerável rapidez, a quantidade mínima de leite produzida por uma vaca em duas ordenhas, a partir da qual será economicamente viável a realização da terceira ordenha.

\section{AGRADECIMENTOS}

Os autores agradecem a Fundação de Amparo a Pesquisa do Estado de Minas Gerais (FAPEMIG), pelo apoio na realização deste trabalho; e ao CNPq, pela concessão de bolsa de produtividade em pesquisa (PQII) ao primeiro autor.

\section{REFERÊNCIAS}

ALVES, M. Robotização da ordenha em vacas leiteiras. Escola Superior Agrária de Castelo Branco, 2004. Disponível em: <http://docentes.esa.ipcb.pt/bovinosdeleite/aamalves.pdf >. Acesso em: 09 set. 2009.

AMOS, H. E.; KISER, T.; LOEWENSTEIN, M. Influence of milking frequency on productive and reproductive efficiencies of dairy cows. Journal of Dairy Science, Georgia, v. 68, n. 3, p. 732-739, 1985.

BAR-PELED, U., E.MALTZ, I. BRUCKENTAL, Y. FOLMAN, Y. KALI, H. GACITUA, A.R. LEHRER, C.H. KNIGHT, B. ROBINSON, H. VOET, H. TAGARI. Relationship between frequent milking or suckling in early lactation and milk production of high producing dairy cows. Journal of Dairy Science, Champaign, v. 78, n. 12, p. 2726-2736, 1995.

BERNIER-DODIER, P.; DELBECCHI, L.; WAGNER, G.F.; TALBOT, B.G.; LACASSE, P. Effect of milking frequency on lactation persistency and gland remodeling in mid-lactation cows 1. Journal of Dairy Science, Champaign, v. 93, n. 2, p. 555-564, Feb. 2010.

CAMINHA, F. O.; GONÇALVES, A. de C. Quando aumentar o número de ordenhas. 2003. Disponível em: $<$ http://www.milkpoint.com.br/?noticiaID

$=8713 \&$ act $\mathrm{A}=7 \&$ areaID $=61 \&$ secaoID $=159>$. Acesso em: 09 set. 2009.

DAHL, G.E. Frequent milking in early lactation: considerations for implementation. In: Florida Dairy Production Conference, 42., 2005, Gainesville. Disponível em: dairy.ifas.ufl.edu/dpc/2005/Dahll.pdf. Acessado em: 01/12/2011.

DIAS, H. S. Ordenhar: quantas vezes por dia? 2005. Disponível em: <http://www.rehagro.com.br/siterehagro/publicacao.do?cd noticia=722>. Acesso em: 09 set. 2009.

ERDMAN, R. A.; VARNER, M. Fixed yield responses to increased milking frequency. Journal of Dairy Science, Champaign, v. 78, n. 5, p. 1199-1203, 1995.
GAMA, M. A. S.; LOPES, F. C. F. Alteração da frequência de ordenha: aspectos produtivos e econômicos. Revista DBO Mundo do Leite, São Paulo, v. 29, p. 1719, 2008.

HEBERT, C. Never 2 without 3? Impact of the increase of milking frequency. Producteur-de lai-Quebecois, v. 23, n. 3, p. 22-25, 2002.

HOMAN, E. J.; WATTIAUX, M. A. Lactation and milking. Madison: Babcock Institute for International Dairy Research and Development/University of Winsconsin, 1995. chap. 25.

IBGE, 2006. Instituto Brasileiro de Geografia e Estatística (IBGE). Porcentagem de mão de obra familiar na sociedade brasileira. http://www.ibge.gov.br/home/presidencia/noticias/noticia _visualiza.php?id_noticia=1466\&id_pagina $=1$

KELLY, A.L.; REID, S.; JOYCE, P.; MEANEY, W.J.; FOLEY, J. Effect of decreased milking frequency of cows in late lactation on milk somatic cell count, polymorphonuclear leucocyte numbers, composition, and proteolytic activity. Journal of Dairy Research, Cork, v. 65, n. 3, p. 365-373, 1998.

KLEI, L.R.; LYNCH, J.M.; BARBANO, D.M.; OLTENACU, P.A.; LEDNOR, A.J.; BANDLER, D.K. Influence of milking three times a day on milk quality. Journal of Dairy Science, Champaign, v. 80, n. 3, p. 427436, 1997.

LOPES, M.A.; CARDOSO, M.G., CARVALHO, F. de M., LIMA, A.L.R., DIAS, A.S. \& CARMO, E.A. do. Efeito da escala de produção nos resultados econômicos de sistema de produção de leite na região de Lavras (MG) em 2004 e 2005. Archivos Latinoamericanos de Producción Animal. San Ivan, v.16, n.3. p. 121-129, 2008.

LOPES, M. A.; LIMA, A.L.R.; CARVALHO, F. de M.; REIS, R.P.; SANTOS, I.C.; SARAIVA, F.H. Efeito do tipo de mão-de-obra nos resultados econômicos de sistemas de produção de leite na região de Lavras (MG): um estudo multicasos. Revista Ceres, Viçosa, v. 54, n. 312, p. 173-182. 2007.

LOPES, M.A. LIMA, A.L.R.; CARVALHO, F. de M.; REIS, R.P.; SANTOS, I.C.; SARAIVA, F.H. Efeito do tipo de sistema de criação nos resultados econômicos de sistemas de produção de leite na região de Lavras, MG. Ciência e Agrotecnologia, Lavras, v. 28, n. 5, p. 1177 1189, set./out. 2004.

MARTINS, E. Contabilidade de custos. 9. ed. São Paulo: Atlas, 2008. 378 p.

MATSUNAGA, M.; BEMELMANS, P.F.; TOLEDO, P.E.N. de; DULLEY, R.D.; OKAWA. H.; PEDROSO, I.A. Metodologia de custo de produção utilizado pelo IEA. Agricultura em São Paulo, São Paulo, v. 23, n. 1, p. 123139, 1976.

MOYA, S. L.; GÓMEZ, M.A.; BOYLE, L.A.; MEE, J.F.; O'BRIEN, B.; ARKINS, S. Effects of milking frequency 
on phagocytosis and oxidative burst activity of phagocytes from primiparous and multiparous dairy cows during early lactation. Journal of Dairy Science, Champaign, v. 91, n. 2, p. 587-595, Feb. 2008.

NEGRÃO, J. A. Manejo para produção de leite de alta qualidade. Aspectos fisiológicos relacionados à síntese e ejeção do leite. In: Zootec 2004. Brasília, 2004. p. 1-7. Disponível em http://www.abz.org.br/files.php?file=documentos/Manejo _para_produ 43.pdf, Acesso em 30 setembro de 2012.

SMITH, J.W.; ELY, L.O.; GRAVES, W.M.; GILSON, W.D. Effect of milking frequency on DHI performance measures. Journal of Dairy Science, Champaign, v. 85, n. 12, p. 3526-3533, 2002.

VASCONCELLOS, P. M. B. Conhecimentos gerais, ordenha: tipos de ordenha (manual e mecânica). In: Guia prático para o fazendeiro. 16. ed. São Paulo: Nobel, 1975. cap. VII, p. 215-232.

Protocolado em: 22 dez. 2011. Aceito em: 31 ago. 2012. 